\title{
Identifying Caregivers and Their Meaning for Patients with Metastatic Solid Tumours in Routine Care: A Survey at a Community-Based Oncology Group Practice in Germany
}

\author{
Rudolf Weide ${ }^{1}$, Stefan Feiten ${ }^{2}$, Vera Friesenhahn ${ }^{2}$, Jochen Heymanns ${ }^{1}$, Kristina Kleboth ${ }^{2}$, \\ Ulrike Mergenthaler ${ }^{2}$, Jörg Thomalla ${ }^{1}$, Christoph van Roye ${ }^{1} \&$ Hubert Köppler ${ }^{1}$ \\ ${ }^{1}$ Praxisklinik für Hämatologie und Onkologie, Koblenz, Germany \\ ${ }^{2}$ Institut für Versorgungsforschung in der Onkologie, Koblenz, Germany \\ Correspondence: Rudolf Weide, Praxisklinik für Hämatologie und Onkologie, Neversstr. 5, 56068 Koblenz, \\ Germany. Tel: 49-261-304-930. E-mail: weide@onkologie-koblenz.de
}

Received: March 27, 2012 Accepted: April 9, 2012 Online Published: May 1, 2012

doi:10.5539/cco.v1n1p41 URL: http://dx.doi.org/10.5539/cco.v1n1p41

\begin{abstract}
Purpose: To determine the importance of different contact persons for patients with metastatic solid tumours treated in a community-based oncology group practice. Methods: Psychosocial distress was measured between 04-07/2009 using the distress thermometer and problem list. All patients were asked 3 questions: To whom do you talk, when you are distressed? Which persons are helpful to reduce your distress? How did helpful persons help you? Results: 202 patients with a median age of 68 years (37-85) completed the interview. Most important contact persons named by patients were: oncologist $(84 \%)$, partner $(71 \%)$, children $(64 \%)$, friends $(53 \%)$ and general practitioner (52\%). The most helpful persons were oncologist $(97 \%)$, friends $(94 \%)$, partner $(92 \%)$, children (92\%) and general practitioner (91\%) and the most important qualities of help were listening, patience and mindfulness. The most important qualities of help from the oncologist were: therapy, listening and information/advice. Conclusion: Patients with metastatic solid tumours use a helping network of contact persons when they are distressed. The oncologist, partner, children, friends and general practitioner are key persons. Training of oncologists in distress management is of utmost importance. Furthermore the patient's network should be strengthened by improving the information flow and by continuous support for the main caregivers.
\end{abstract}

Keywords: caregiver, metastatic solid tumour, outpatient, psycho-oncology, psychosocial distress, routine care

\section{Introduction}

"Distress is a multifactorial unpleasant emotional experience of a psychological (cognitive, emotional, behavioural), social, and/or spiritual nature that may interfere with the ability to cope effectively with cancer, its physical symptoms and its treatment. Distress extends along a continuum, ranging from common normal feelings of vulnerability, sadness and fears to problems that can become disabling, such as depression, anxiety, panic, social isolation, and existential and spiritual crisis." This quotation from the NCCN's distress management manual (NCCN Guidelines for Supportive Care - Distress Management, 2011) summarizes effectively the problems we are dealing with in a significant number of patients with cancer. We know from studies that $20-40 \%$ of cancer patients suffer at least from one form of distress during the course of their disease. Reports suggest that $25-50 \%$ of patients have psychological problems, with at least $25 \%$ meeting the criteria for either a major depressive disorder or adjustment disorder with depressed mood (Derogatis et al., 1983; Sellick \& Crooks, 1999). In patients with metastatic solid tumours distress is present in almost every patient during the course of the disease, because of myriads of possible disease- and therapy-related symptoms and the fact that the vast majority of patients will, despite therapy, eventually die due to disease progression. The key questions during the patient-oncologist-relationship are whether distress is present, how severe distress is judged by the patient and which areas of distress are involved. We know from several studies that the personal judgement of oncologists, whether a patient is distressed or not is fairly incorrect and misjudgements may be as high as $35 \%$ (Newell, Sanson-Fisher, Girgis, \& Bonaventura, 1998; Passik et al., 1998; Fallowfield, Ratcliffe, Jenkins \& Saul, 2001). Therefore different distress screening instruments have been developed, validated and implemented in routine care during the last 10 years. One of the most frequently used short screening instruments is the NCCN's distress thermometer (DT) and problem list (PL) (Holland, 2003; Jacobsen et al., 2005; Mitchell, 2007). This screening 
instrument has been successfully used and has shown robustness not only in hospital settings but also in the community based oncology group practice (Mergenthaler et al., 2011). If distress is detected, several other questions arise within the oncology team:

- Is intervention necessary?

- Which intervention should be applied?

- Who should intervene?

- Is the intervention by the oncology team sufficient or should other disciplines (e.g. psychiatry, psychology, social services, clergy) be contacted?

During the last 25 years more than 350 community based oncology practices with more than 600 medical oncologists have been founded in Germany caring for more than 500.000 cancer patients per year (BNHO, 2010). From the patient's point of view community based oncology practices have a couple of advantages compared to clinical settings:

- Patients are cared for by experienced oncologists on a consultant level

- There is continuity in the patient-doctor-relationship throughout the course of the disease sometimes over a decade or even longer

- Patients are treated in close proximity to their homes

Disadvantages compared to large cancer centres may be that helping services dealing with distress management like psychiatry, psychology or social services are not always within one building and may not be approachable in a timely manner due to personal shortages. Thus it was the aim of this survey to learn more about the supporting network concerning distress management of patients with metastatic solid tumours who receive routine treatment in a community based oncology group practice.

\section{Methods}

The study was conducted by the Institute for Health Care Research in Oncology (InVO), Koblenz, Germany. It took place in a community based oncology group practice in Koblenz, where 5 medical oncologists are caring for 4000 patients per year. Patients with metastatic solid tumours visiting the practice between 01/04/2009 $31 / 07 / 2009$ were informed and gave written informed consent before they were interviewed in a separated room of the InVO. The standardized interview was developed by InVO.

Patients were asked 3 questions:

1. To whom do you talk, when you are distressed?

This was an open-ended question and the patient had to answer spontaneously without additional help. No predefined answers were told or shown after the question, the patient named his or her important contact persons freely. Thereafter a list of possible contact persons was shown to the patient (table 1) and the same question was asked again (aided).

2. Which persons are helpful to reduce your distress?

While answering this question the patient chose from a list of possible contact persons (Table 1).

3. How did helpful persons help you?

The patient chose from a list showing different qualities of help (Table 2). 
Table 1. List of possible contact persons

\begin{tabular}{l}
\hline Partner \\
Children \\
Family members \\
Friends \\
Oncologist \\
General practitioner \\
Psychotherapist \\
Clergy \\
Nurse / male nurse \\
Counsellor: cancer information centre \\
Counsellor: rehabilitation \\
Counsellor: social services of non-profit organizations \\
Counsellor: social services of health insurances \\
Member of self-help group \\
Hospice staff member \\
\hline
\end{tabular}

Table 2: List of different qualities of help

\begin{tabular}{l}
\hline Listening / interest \\
Patience \\
Mindfulness / understanding \\
Organization / help at home \\
Giving hope \\
Care / helpfulness \\
Information / advice \\
Diversion \\
Sympathy \\
Security / confidence \\
Dedication \\
Friendliness / enjoyment \\
Openness / honesty \\
\hline
\end{tabular}

All data were collected in a database and analysed statistically using SPSS. Frequencies, medians and means were computed; mean differences were tested for statistical significance by t-tests for independent samples and by single factor variance analyses (ANOVA).

\section{Results}

\subsection{Patient Characteristics}

Between 04-07/2009 a total of 229 patients were approached of whom 27 (12\%) refused the interview. 202 patients with a median age of 68 years (37-85) were interviewed. Patient characteristics are shown in table 3 . The majority of patients suffered from metastatic cancers of the breast $(40 \%)$, colon/rectum (11\%), prostate (10\%), lung $(7 \%)$, ovary $(5 \%)$ and renal cancer (7\%). Concerning therapy $55 \%$ received palliative chemotherapy (41\% iv, $14 \%$ oral), $17 \%$ antihormonal therapy, $10 \%$ a bisphosphonate and $6 \%$ immunotherapy. By the time of this writing (April 2012) 120 of the 202 patients (59\%) have died. The median overall survival since diagnosis of metastasis was 58 months $(3-288+)$. There was no statistically significant difference in the median survival time of men (57 months) and women (60 months) or between age groups (46 - 65 months). 
Table 3. Patient characteristics

\begin{tabular}{|c|c|}
\hline \multicolumn{2}{|l|}{ Age groups } \\
\hline less than 50 years & $9 \%$ \\
\hline $50-59$ years & $19 \%$ \\
\hline $60-69$ years & $32 \%$ \\
\hline $70-79$ years & $34 \%$ \\
\hline 80 years and older & $5 \%$ \\
\hline \multicolumn{2}{|l|}{ Median: 68 years $(37-85)$} \\
\hline \multicolumn{2}{|l|}{ Gender } \\
\hline male & $35 \%$ \\
\hline female & $65 \%$ \\
\hline \multicolumn{2}{|l|}{ Tumour site } \\
\hline breast & $40 \%$ \\
\hline colon + rectum & $11 \%$ \\
\hline prostate & $10 \%$ \\
\hline lung & $7 \%$ \\
\hline renal cancer & $7 \%$ \\
\hline ovary & $5 \%$ \\
\hline cancer of unknown primary (CUP) & $3 \%$ \\
\hline pancreas & $3 \%$ \\
\hline skin & $2 \%$ \\
\hline cervix / uterus & $2 \%$ \\
\hline stomach & $2 \%$ \\
\hline others & $6 \%$ \\
\hline \multicolumn{2}{|l|}{ Type of therapy } \\
\hline chemotherapy iv & $41 \%$ \\
\hline antihormonal therapy & $17 \%$ \\
\hline oral chemotherapy & $14 \%$ \\
\hline bisphosphonates & $10 \%$ \\
\hline immunotherapy & $6 \%$ \\
\hline watchful waiting & $6 \%$ \\
\hline therapy break & $3 \%$ \\
\hline diagnosis (no therapy) & $1 \%$ \\
\hline best supportive care & $0,5 \%$ \\
\hline radiation & $0,5 \%$ \\
\hline \multicolumn{2}{|l|}{ Cases of death within 21-24 months } \\
\hline cases of death & $59 \%$ \\
\hline survival rate & $41 \%$ \\
\hline
\end{tabular}

\subsection{Distress Outcomes}

Concerning distress the mean distress level was 4.4 with $30 \%$ of patients scoring above 5, thus fulfilling criteria for intervention according to the "Working Committee Psychooncology of the German Society for Haematology and Oncology (Arbeitskreis Psychoonkologie der DGHO)" (Mehnert, Müller, Lehmann \& Koch, 2006). Women 
(4.6) showed a higher distress level compared to men (3.8) $(\mathrm{p}=0.038)$. Statistically not significant was the mean difference between age groups, maybe due to lacking statistical power of the conducted ANOVA. To enhance the power only two groups of younger (68 years and younger) and older patients (older than 68 years) according to the median age were analysed. Older patients showed less distress (4.1) than younger (4.6) but the computed t-test also failed to reach statistical significance. Further variance analyses showed no significant association between type of therapy and level of distress or between tumour site and level of distress. Patients who died during the observation period (4.3) and patients who survived (4.4) scored quite comparable, therefore no association between survival (from a retrospective view) and distress could be confirmed. The proportion of persons scoring above cut-off ( $>5)$, which means they experience significant distress, is depicted in table 4 .

Problems most frequently described were physical (92\%), emotional (63\%), practical (14\%), family (12\%) and spiritual (4\%).

Table 4. Proportion of patients scoring above cut-off $(>5)$

\begin{tabular}{ll}
\hline Total & $30 \%$ \\
\hline Age groups & $37 \%$ \\
\hline less than 50 years & $33 \%$ \\
50 - 59 years & $28 \%$ \\
60 - 69 years & $31 \%$ \\
70 - 79 years & $18 \%$ \\
80 years and older & \\
\hline Gender & $23 \%$ \\
male & $34 \%$ \\
female & \\
\hline Tumour site & $38 \%$ \\
\hline breast & $30 \%$ \\
colon + rectum & $30 \%$ \\
prostate & $33 \%$ \\
lung & $13 \%$ \\
renal cancer & $27 \%$ \\
ovary & $21 \%$ \\
others & $35 \%$ \\
\hline Type of therapy & $26 \%$ \\
\hline chemotherapy iv & $25 \%$ \\
antihormonal therapy & $20 \%$ \\
oral chemotherapy & $21 \%$ \\
bisphosphonates & $31 \%$ \\
immunotherapy & \\
watchful waiting & $29 \%$ \\
\hline others & \\
\hline death within the observation period & $31 \%$ \\
survival & 30 \\
\hline & \\
\hline
\end{tabular}




\subsection{Support persons}

The 6 most important contact persons (question 1) were as follows: oncologist (84\%), partner (71\%), children (64\%), friends (53\%), general practitioner (52\%) and family members (45\%).

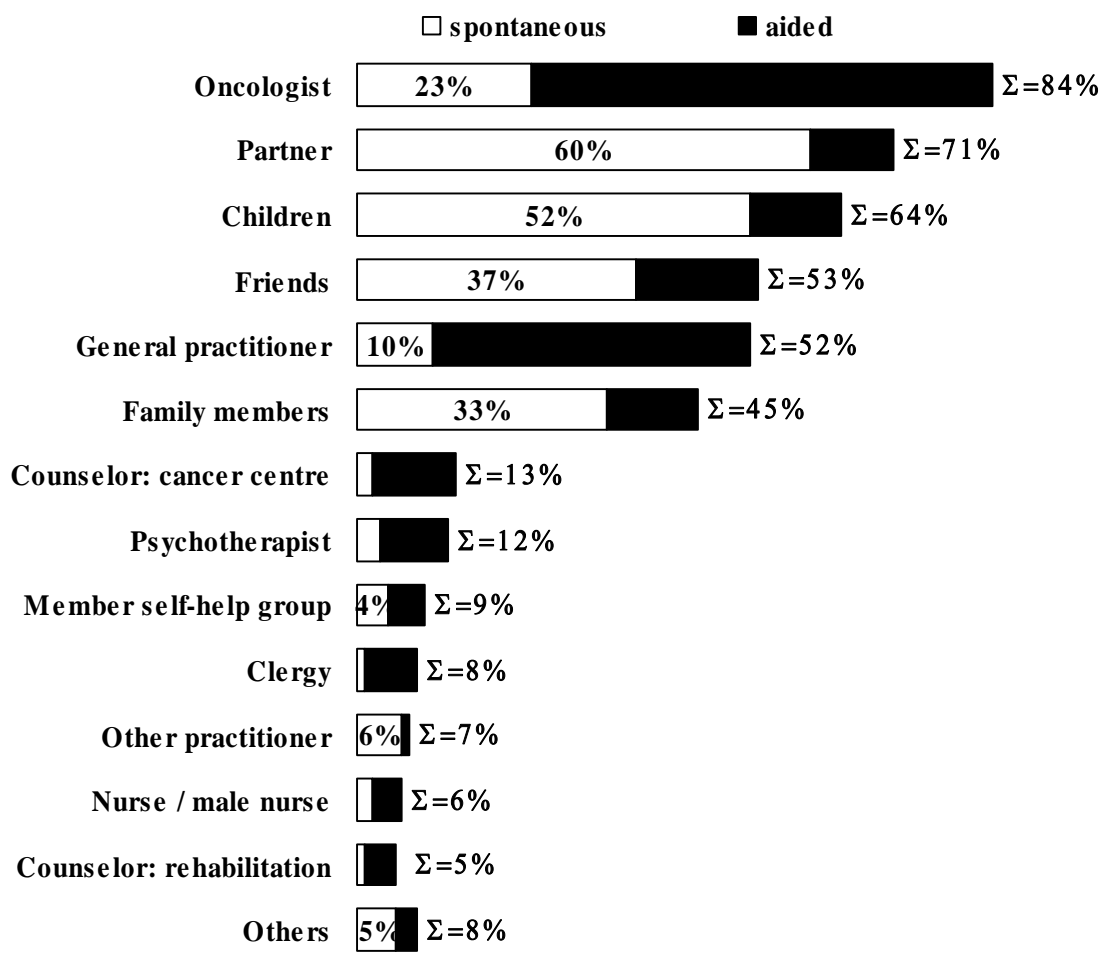

Figure 1. Most important contact persons (question 1)

spontaneous: open-ended question without predefined answers

aided: repetition of the question and presentation of a list of possible contact persons

The distribution of contact persons according to age and gender revealed that the oncologist is an equally important contact person for all age groups and both genders.

Differences between genders were observed and showed that women use more often their children, whereas men use most frequently, beside the oncologist, their spouses as contact persons. Women use more frequently friends, family members, psychotherapists, and self-help groups. Generally women use significantly more different contact persons (4.6), compared to men (3.9) $(\mathrm{p}=0.019)$. Younger patients more often seek help in friends and family members, whereas older patients tend to contact more often their children. Younger patients contact more often psychotherapists or self-help groups.

The 6 most helpful persons (question 2) named by more than 90 patients were as follows: oncologist (97\%), friends $(94 \%)$, partner $(92 \%)$, children $(92 \%)$, general practitioner $(91 \%)$ and family members $(88 \%)$. Overall contacts to psychotherapists, counsellors (cancer centre) and self help groups were described as slightly less helpful.

\subsection{Qualities of Help}

The 5 most important qualities of help (question 3) were: listening, patience, mindfulness, giving hope, and help at home. The 5 most important qualities of help from the oncologist were: therapy, listening, information/advice, mindfulness and giving hope. A detailed analysis of the qualities of help is depicted in table 5 . 
Table 5. Most important qualities of help

\begin{tabular}{lcccccc}
\hline & $\begin{array}{c}\text { Partner } \\
(n=131)\end{array}$ & $\begin{array}{c}\text { Children } \\
(n=119)\end{array}$ & $\begin{array}{c}\text { Family } \\
\text { members } \\
(n=80)\end{array}$ & $\begin{array}{c}\text { Friends } \\
(n=101)\end{array}$ & $\begin{array}{c}\text { Oncologist } \\
(n=165)\end{array}$ & $\begin{array}{c}\text { General } \\
\text { practitioner } \\
(n=96)\end{array}$ \\
\hline Listening/ interest & $58 \%$ & $60 \%$ & $63 \%$ & $65 \%$ & $38 \%$ & $49 \%$ \\
Patience & $43 \%$ & $31 \%$ & $25 \%$ & $33 \%$ & $13 \%$ & $16 \%$ \\
Mindfulness & $41 \%$ & $31 \%$ & $36 \%$ & $39 \%$ & $21 \%$ & $26 \%$ \\
Organization/ help at home & $33 \%$ & $26 \%$ & $33 \%$ & $10 \%$ & - & - \\
Giving hope & $37 \%$ & $28 \%$ & $21 \%$ & $24 \%$ & $19 \%$ & $18 \%$ \\
Care/ helpfulness & $11 \%$ & $14 \%$ & $11 \%$ & $7 \%$ & $2 \%$ & $9 \%$ \\
Information/ advice & $5 \%$ & $12 \%$ & $9 \%$ & $13 \%$ & $37 \%$ & $32 \%$ \\
Diversion & $4 \%$ & $6 \%$ & $4 \%$ & $15 \%$ & - & - \\
Security/ confidence & $2 \%$ & $2 \%$ & - & $2 \%$ & $18 \%$ & $10 \%$ \\
Therapy & - & - & - & - & $56 \%$ & $4 \%$ \\
\hline
\end{tabular}

\section{Discussion}

Distress and distress management is an important issue in oncology, especially in patients with metastatic solid tumours. Studies reveal that almost all patients in this group show some form of distress with $20-40 \%$ of patients scoring above average (NCCN Guidelines for Supportive Care - Distress Management, 2011; Derogatis et al., 1983; Sellick \& Crooks, 1999; Mergenthaler et al., 2011). Highest psychological distress has been reported in patients with metastatic solid tumours receiving chemotherapy (Herschbach et al., 2008). In western societies more and more patients with cancer are treated in the community close to their living homes. During the last 25 years more than 350 oncology group practices with more than 600 oncologists have been founded in Germany caring for more than 500.000 patients per year. Advantages are that patients are treated close to their homes by experienced oncologists and that there is continuity of care, which is especially important in patients with metastatic solid tumours. A study looking at patients with inoperable lung cancer found that one of the most distressing concerns of patients was no continuity of patient care in the hospital setting ("too many doctors are caring for me"). More than one quarter reported significant distress caused by the health system (Tishelman, Lövgren, Broberger, Hamberg \& Sprangers, 2010). Disadvantages compared to cancer centres may be that consultation visits are often short due to time constraints and psychosocial services are understaffed or too far away leading to a shortage of psychosocial support in routine care. No data exist so far which contact persons are important for patients with metastatic solid tumours concerning distress-reduction, who are treated in a community based oncology practice.

We undertook this study to ask our patients whom they call on most frequently when they are distressed to learn more about the supporting network of patients with metastatic solid tumours who are treated outside academic centres in routine care:

- To whom do you talk, when you are distressed?

It was interesting for us to see that nearly all patients have some form of a supporting network and that the oncologist, partner, children, general practitioner and family members play a major role in this network.

- Which persons are helpful to reduce your distress?

The oncologist, friends, partner, children, general practitioner and other family members were considered most helpful in distress reduction.

- How did helpful persons help you?

Listening, patience, mindfulness and giving hope were the main qualities of help in all contact persons.

Therapy, information and advice were additional main qualities of the oncologist but listening, mindfulness and giving hope were also considered important qualities of help.

Within this supporting network qualities of help are distributed differently between doctors and main care givers. Certain qualities are demanded predominantly from partners, children, friends and family members, others are expected mainly from the oncologist and general practitioner. But there are only a few qualities which belong exclusively to a certain group of supporters, i.e. therapy, help at home or diversion. 


\subsection{The Task of the Oncologist}

These findings underline the patient's wish that cancer care for the whole patient is demanded from the oncologist. The 2007 report from the Institute of Medicine, which is based on randomized clinical trials, reviews and metaanalyses, clearly pointed out that quality of cancer care must integrate psychosocial needs of the patients in routine care (Adler \& Page, 2008). A well functioning doctor-patient communication correlates with numerous aspects such as enhanced quality of life, medical adherence and patient satisfaction, whereas malfunctioning communication is associated with increased levels of anxiety, depression, anger and confusion (Holland, 2003; Lerman et al., 1993; Heussner, Huber \& Sellschopp, 2006; Lehmann, Koch \& Mehnert, 2009). If terminal ill cancer patients are asked what matters most in end-of-life care, they say that trust and confidence in the doctors looking after them is most important and that information about the disease should be communicated by the doctor in an honest manner (Heyland et al., 2006).

Within a team of specialists caring for patients with metastatic solid tumours the medical oncologist plays a central role concerning diagnosis, prognosis, therapy and continuing communication with patients and relatives. Patients and relatives rely and trust on the experience and knowledge of their oncologist concerning state of the art diagnostic procedures, surgical options, chemotherapy, immunotherapy, targeted therapy, radiotherapy, supportive therapy and palliative care. Besides that, patients and relatives expect communication skills, empathy, sensitivity and mindfulness to explain treatment options, symptom management and skills concerning distress management. During medical training much emphasis is put on training in diagnostic procedures, pharmacology, biochemistry, molecular biology and their clinical application to most effectively achieve a cytotoxic effect on the tumour.

The effectiveness of such interventions is measured in response rates, progression free and overall survival. The focus of the oncology training thus in the western world is to become an expert in somatic medicine with two main goals: Cure and prolongation of life.

Therefore questions from the patient's point of view, especially from patients with metastatic solid tumours, where cure is rarely achieved, may frequently be overlooked: How long may I live with this cancer? What means quality of life for me? Which therapy associated side effects am I prepared to accept? What are the main goals for me now in life? Which goals do I want to achieve? Which goals are realistic? Who may be of help to me apart from the oncology team? Who may be part of a network of people supporting me when life gets tough?

These essential questions can only be heard and dealt with if the oncologist is trained in communication and distress management skills. From studies we know, that the judgment of oncologists whether patients are distressed or have psychiatric co-morbidities is fairly incorrect (Newell et al. 1998; Passik et al., 1998; Fallowfield et al., 2001). Therefore measuring distress using validated self reporting instruments like the DT and PL is necessary for every oncologist caring for patients (NCCN Guidelines for Supportive Care - Distress Management, 2011). Measuring and qualifying distress enables the oncologist to answer important questions:

- Is significant distress present?

- Which are the causes of distress?

- Is intervention necessary?

- Does the patient wish intervention?

- Who should intervene?

Especially the last questions are important for the oncologist to decide whether the options of intervention of the oncology team are sufficient or if other services (e.g. psychiatry, psychotherapy, psychology, social services, clergy) are needed. A study from Australia reported that 33\% of oncologists with direct patient contact complained about high levels of emotional exhaustion. The main predictors of burnout were dissatisfaction with leave arrangements for recovering from burnout, increased hours of patient contact and perceived need for communication skill training (Girgis, Hansen \& Goldstein, 2008). Thus from the patient's and oncologist's point of view it deserves high priority to observe the above mentioned requirements for a high quality patient care in oncology.

\subsection{The Role of Relatives and Friends}

Relatives and friends play a central role within the supporting network for patients with metastatic solid tumours in our survey. This is supported by a study in terminal ill cancer patients who received end-of-life care in hospitals, where the majority of patients had family members or friends who visited them regularly in hospital (Girgis et al., 2008). Another study in women with advanced breast cancer found positive social support by 
relatives and friends associated with significantly less life stress (Koopman, Hermanson, Diamond, Angell \& Spiegel, 1998).

In a study looking at psychosocial needs of close relatives of women under treatment for breast cancer most relatives demanded honest treatment information and complained about difficulties with confidence in health care professionals. The majority suffered from distress and a significant proportion from anxiety and depression (Schmid-Büchi, van den Borne, Dassen \& Halfens, 2011). Thus honest information about treatment options and prognosis for patients and relatives must be an integral part of patient care in oncology. Psychosocial needs for relatives and friends should always be remembered.

\subsection{The Role of the General Practitioner}

The general practitioner was considered one of the most important contact persons by the patients concerning distress management and distress reduction within our survey. This underlines the importance of communication and information flow between the oncologist, relatives, friends and the general practitioner who looks after the patient at home.

\subsection{The Role of Psychotherapists}

It was interesting for us to see, that within this group of severely ill patients only $12 \%$ named psychotherapists as helpful persons, although all patients were offered the opportunity to get in contact to a psychotherapist. This may be due to the fact that all patients lived in families or with partners and therefore felt that they had sufficient emotional support from relatives and friends. Another explanation may be the fact that each of the 5 oncologists had more than 20 years of communication experience in oncology and was qualified in palliative care and psychopharmacotherapy and therefore was functioning as a psychooncologist as well. We like to speculate that the question how many patients do need psychotherapy is dependent on psychiatric comorbidity, and on the quality and quantity of emotional support the patient receives from other sources (relatives, friends, general practitioner and oncologist). Especially important are continuity of care and experience and communication skills of the oncologist.

Limitations of our study are that it was carried out in close proximity to the place of treatment and that the interview was performed by personnel of InVO which may have influenced the answers of the patients concerning the importance of the oncologist. On the other hand one has to consider the severe illness of our patient cohort (59\% have died at the time of this writing) and the fact that this study would have been difficult to conduct by an external research company due to a lack of trust and confidence and necessary additional arrangements between patients, caregivers and unknown personnel of a research company. An anonymous patient self-report may have reduced the number of patients who were willing to participate and the completeness and quality of the answers.

The disparity between spontaneous and aided nominations of oncologists and general practitioners may be due to the fact that these severely ill patients see their oncologist and general practitioner very frequently and thus may view these contacts as "normal". An answering bias concerning this question can't be excluded.

\section{Conclusion}

In conclusion this is the first report showing the importance of the supporting network for the coping process of patients with metastatic solid tumours who are cared for in a community based oncology practice. Most important persons from the patient's point of view are the oncologist, partner, children, friends and general practitioner. The majority of patients demand from their oncologist care of the whole patient including psychosocial aspects of care. Patients demand empathy, trust, confidence and continuity of care. Thus we conclude that it is of utmost importance to train communication and distress management skills in oncologists. Furthermore we learned that it is equally important to strengthen the patient's network by intensifying the information flow and communication between all persons involved and by supporting the main caregivers. 


\section{References}

Adler, N. E., \& Page, A. E. K. (Eds.). (2008). Cancer care for the whole patient: Meeting psychosocial health needs. Washington, D.C.: The National Academies Press.

BNHO. (2010). Retrieved November, 30, 2010 from http://www.bnho.de/index.htm

Derogatis, L. R., Morrow, G. R., Fetting, J., Penman, D., Piasetsky, S., Schmale, A. M., ... Carnicke, C. L. Jr. (1983). The prevalence of psychiatric disorders among cancer patients. Journal of the American Medical Association, 249, 751-757. http://dx.doi.org/10.1001/jama.1983.03330300035030

Fallowfield, L., Ratcliffe, D., Jenkins, V., \& Saul, J. (2001). Psychiatric morbidity and its recognition by doctors in patients with cancer. British Journal of Cancer, 84, 1011-1015. http://dx.doi.org/10.1054/bjoc.2001.1724

Girgis, A., Hansen, V., \& Goldstein, D. (2008). Are Australian oncology health professionals burning out? A view from the trenches. European Journal of Cancer, 45, 393-399. http://dx.doi.org/10.1016/j.ejca.2008.09. 029

Herschbach, P., Book, K., Brandl, T., Keller, M., Lindena, G., Neuwöhner, K., \& Marten-Mittag, B. (2008). Psychological distress in cancer patients assessed with an expert rating scale. British Journal of Cancer, 99, 37-43. http://dx.doi.org/10.1038/sj.bjc.6604420

Heussner, P., Huber, B., \& Sellschopp, A. (2006). Integrierte psycho-onkologische Diagnostik im Rahmen eines Clinical Cancer Centers. Psychoonkologie, 175-180.

Heyland, D. K., Dodek, P., Rocker, G., Groll, D., Gafni, A., Pichora, D., ... Lam, M.; Canadian Researchers End-of-Life Network (CARENET). (2006). What matters most in end-of-life care: perceptions of seriously ill patients and their family members. Canadian Medical Association Journal, 174, 627-633. http://dx.doi.org/10.1503/cmaj.050626

Holland, J. C. (2003). American Cancer Society Award Lecture. Psychological care of patients: Psycho-Oncology's contribution. Journal of Clinical Oncology, 21, 253-265. http://dx.doi.org/10.1200/JCO. 2003.09.133

Jacobsen, P. B., Donovan, K. A., Trask, P. C., Fleishman, S. B., Zabora, J., Baker, F., \& Holland, J. C. (2005). Screening for psychologic distress in ambulatory cancer patients. Cancer, 103, 1494-1502. http://dx.doi.org/10.1002/cncr.20940

Koopman, C., Hermanson, K., Diamond, S., Angell, K., \& Spiegel, D. (1998). Social support, life stress, pain and emotional adjustment to advanced breast cancer. Psychooncology, 7, 101-111. http://dx.doi.org/10.1002/(SICI)1099-1611(199803/04)7:2<101::AID-PON299>3.0.CO;2-3

Lehmann, C., Koch, U., \& Mehnert, A. (2009). Die Bedeutung der Arzt-Patient-Kommunikation für die psychische Belastung und die Inanspruchnahme von Unterstützungsangeboten bei Krebspatienten: Ein Literaturüberblick über den gegenwärtigen Forschungsstand unter besonderer Berücksichtigung patientenseitiger Präferenzen. Psychotherapie, Psychosomatik, Medizinische Psychologie, 59(7), 3-27. http://dx.doi.org/10.1055/s-2008-1067443

Lerman, C., Daly, M., Walsh, W. P., Resch, N., Seay, J., Barsevick, A., ... Martin, G. (1993). Communication between patients with breast cancer and health care providers. Determinants and implications. Cancer, 72 , 2612-2620. http://dx.doi.org/10.1002/1097-0142(19931101)72:9<2612::AID-CNCR2820720916>3.0.CO; $2-\mathrm{F}$

Mehnert, A., Müller, D., Lehmann, C., \& Koch, U. (2006). Die Deutsche Version des NCCN Distress Thermometers. Zeitschrift für Psychiatrie, Psychologie und Psychotherapie, 54, 213-223. http://dx.doi.org/10.1024/1661-4747.54.3.213

Mergenthaler, U., Heymanns, J., Köppler, H., Thomalla, J., van Roye, C., Schenk, J., \& Weide, R. (2011). Evaluation of psychosocial distress in patients treated in a community-based oncology group practice in Germany. Annals of Oncology, 22, 931-938. http://dx.doi.org/10.1093/annonc/mdq455

Mitchell, A. J. (2007). Pooled results from 38 analyses of the accuracy of distress thermometer and other ultra-short methods of detecting cancer-related mood disorders. Journal of Clinical Oncology, 25, 4670-4681. http://dx.doi.org/10.1200/JCO.2006.10.0438

NCCN Guidelines for Supportive Care - Distress Management. (2011). In NCCN Clinical Practice Guidelines in Oncology - NCCN Guidelines [TM]. Retrieved January 10, 2011 from http://www.ncen.org/professionals/ physician_gls/f_guidelines.asp\#supportive 
Newell, S., Sanson-Fisher, R. W., Girgis, A., \& Bonaventura, A. (1998). How well do medical oncologists' perceptions reflect their patients' reported physical and psychosocial problems? Data from a survey of five oncologists. Cancer, 83, 1640-1651. http://dx.doi.org/10.1002/(SICI)1097-0142(19981015)83:8<1640::

AID-CNCR21>3.0.CO;2-\#

Passik, S. D., Dugan, W., McDonald, M. V., Rosenfeld, B., Theobald, D. E., \& Edgerton, S. (1998). Oncologists' recognition of depression in their patients with cancer. Journal of Clinical Oncology, 16, 1594-1600.

Schmid-Büchi, S., van den Borne, B., Dassen, T., \& Halfens, R. J. (2011). Factors associated with psychosocial needs of close relatives of women under treatment for breast cancer. Journal of Clinical Nursing, 20, 1115-1124. http://dx.doi.org/10.1111/j.1365-2702.2010.03376.x

Sellick, S. M., \& Crooks, D. L. (1999). Depression and cancer: an appraisal of the literature for prevalence, detection and practice guideline development for psychological interventions. Psychooncology, 8, 315-333. http://dx.doi.org/10.1002/(SICI)1099-1611(199907/08)8:4<315::AID-PON391>3.0.CO;2-G

Tishelman, C., Lövgren, M., Broberger, E., Hamberg, K., \& Sprangers, M. A. (2010). Are the most distressing concerns of patients with inoperable lung cancer adequately assessed? A mixed-methods analysis. Journal of Clinical Oncology, 28, 1942-1949. http://dx.doi.org/10.1200/JCO.2009.23.3403 